\title{
GOBERNAR ES IGUALAR ISONOMÍA, OPORTUNIDADES Y JUSTICIA SOCIAL EN LA ARGENTINA
}

RAÚL GUSTAVO FERREYRA 
SUMARIO

I. PRELUDIO. II. ESTADO, CONSTITUCIÓN E IGUALDAD. III. CRITERIOS SOBRE LA IGUALDAD. IV. PROSPECTUS. V. COMENTARIOS FINALES. 


\title{
GOBERNAR ES IGUALAR ISONOMÍA, OPORTUNIDADES Y JUSTICIA SOCIAL EN LA ARGENTINA ${ }^{1}$
}

\author{
RAÚL GUSTAVO FERREYRA² \\ «Nessun maggior dolore che ricordarsi \\ del tempo felice ne la miseria...» \\ Dante Alighieri, Divina Commedia, \\ Inferno, Canto Quinto (123)
}

\section{PRELUDIO}

En 1852 Juan Bautista Alberdi, arquitecto de constitucionalidad de la República Argentina, dogmatizó: «... La constitución debe ser hecha para poblar el suelo solitario del país de nuevos habitantes y para alterar y modificar la población actual» ${ }^{3}$. Al relacionar la superficie de la Argentina con sus habitantes, por entonces menos de 1.000.000 de personas abrumadoramente analfabetas, se preguntó qué nombre merecía un país así conformado: «un desierto». Por consiguiente, ¿qué nombre habría de darse a la Constitución de ese país?: «La cons-

1 Agradezco la lectura del texto a los profesores Julio B. J. Maier, Leandro Vergara, Sebastián D. Toledo, Enrique J. Morales, José E. Schuh, Ricardo Rabinovich-Berkman y E. Raúl Zaffaroni, junto a su benévola atención y ulteriores comentarios.

2 Catedrático de Derecho Constitucional, Facultad de Derecho, Universidad de Buenos Aires. Av. Figueroa Alcorta 2263 (C1425CKB). Buenos Aires (Argentina); Doctor de la Universidad de Buenos Aires (Email: rgferreyra@hotmail.com.ar).

3 Alberdi, Juan Bautista, Bases y puntos de partida para la organización política de la República Arjentina, derivados de la lei que preside al desarrollo de la civilización en América del Sud y del Tratado Litoral de 4 de enero de 1831, 2. ${ }^{a}$ ed., correjida, aumentada de muchos parágrafos y de un proyecto de Constitución concebido según las bases propuestas por el autor, Valparaíso, Imprenta del Mercurio, Santos Tornero y Cía., 1852, p. 195. 
titución de un desierto» ${ }^{4}$. Dentro del cerco de su escritura siempre mantuvo un diálogo interno: «¿Cuál es la mejor constitución que conviene al desierto?»: la que sirve para hacer que el desierto deje de serlo en el menor tiempo posible y se constituya una República en un "país poblado» ${ }^{5}$. La tesis de su escritura política puede resumirse en su frase «gobernar es poblar».

Toda escritura se desliza por intermedio de palabras que confieren su composición y movimiento. No ingreso aquí en la semántica ni en la morfología de la citada tesis de Alberdi. Sí, en cambio, me aprovecho en parte de su pura y endurecida sintaxis. Adopto como título para este texto «Gobernar es igualar». Emprendo esta tarea desde una comprensión teórica con vocación constituyente. Es decir, de constitutione ferenda y no tanto de un gobierno ordinario. A la pregunta «¿cuál es la mejor constitución?», respondo: la que se oriente de modo decidido, decisivo e imparcial a terminar con la desigualdad social ${ }^{6}$ y a convertir la República en un país de ciudadanos igualmente incluidos.

¿Qué jurista no ha reflexionado a menudo sobre la pobreza y las situaciones de vulnerabilidad o desamparo social? No existen consensos respecto de las técnicas de su medición; la diáspora de la teoría no ha logrado alimentar a las bocas de una multitud. No basta escribir «menos desigualdad» o «más igualdad social». Según estimaciones formuladas hacia fines de 2015, más de un $25 \%$ de la población urbana ${ }^{7}$ de la Argentina vive en situación de pobreza y casi un $35 \%$ se encuentra en condiciones de vulnerabilidad ${ }^{8}$. Ellos, los desposeídos y vulne-

${ }^{4}$ Ibíd., p. 196.

5 Ibid.

${ }^{6}$ En este trabajo «desigualdad social» o «desigualdad», a secas, siempre se refieren a la «social»; en ambos casos se la distingue de la «desigualdad natural». Por lo tanto, al referirme a la desigualdad producida por la naturaleza entre los hombres, en todos los casos empleo «desigualdad» siempre calificada de «natural». Sobre aspectos fundamentales de la distinción, remito al lector, más adelante, a la sección III.

${ }^{7}$ Más del $90 \%$ de la población total del país asume tal naturaleza.

${ }^{8}$ El Observatorio de la Deuda Social Argentina (ODSA) de la Pontificia Universidad Católica Argentina (UCA) elaboró una «Matriz de Pobreza Multidimensional» que articula el espacio de Bienestar y el espacio de Derechos. Según esta metodología, la población es pobre si sufre de privaciones tanto en el espacio de Bienestar (por ingreso) y, al mismo tiempo, en el espacio de Derechos (al menos una privación en acceso a niveles básicos de alimentación, salud, servicios públicos, vivienda digna, recursos educativos y empleo estable y seguridad social). En caso de que sólo se sufra de carencia en una de las dos dimensiones, el hogar es considerado en situación de vulnerabilidad en la dimensión afectada. Muestra proyectada sobre total de población urbana: pobreza multidimensional, 25,6\% (extrema, 5,3\%; no extrema, 20,3\%); vulnerables por carencias, $28,2 \%$; vulnerables por ingresos, $3,4 \%$; subtotal pobreza + vulnerabilidad: $57,2 \%$; no vulnerables por carencias ni por ingresos, $42,8 \%$; «Evaluación de la pobreza urbana desde un enfoque multidimensional basado en derechos: 2010-2015», Agustín Salvia (coordinador del estudio), Juan 
rables, no tienen conocimiento acabado sobre lo que sucede ni se percatan de aquello que no conocen. «Por lo tanto, se produce una suerte de alienación con respecto a las instituciones», porque, con legitimación suficiente y extendida, los ciudadanos vulnerables «sienten que nada funciona para ellos» 9 .

Nunca existió ni existirá una sociedad igualitaria, con plena igualdad en todos los bienes sociales. Nunca se extinguirá por costumbre natural la desigualdad entre los hombres, cuyas fuentes principales y más odiosas, repugnantes y abominables, son la pertenencia a una etnia, el sexo, la edad o la clase social ${ }^{10}$. Las constituciones poseen, en general, pretensiones sobre las que fundar una cierta idea de eternidad; la de la Argentina en el siglo xIx: una república «esencialmente comercial y pastora» ${ }^{11}$. A lo largo de la historia, se ha maximizado la concentración de la riqueza (tanto la yacente como la creada) y se ha descuidado, con dolo o negligencia, el crecimiento de la pobreza y la vulnerabilidad poblacional. Actualmente, en 2016, la población de la Argentina supera los 43.000 .000 de habitante ${ }^{12}$; la singularidad de la situación que aquí se denuncia — pobreza y vulnerabilidad — aflige a más de la mitad de ellos. Si bien semejante desgarro no será curado solamente con normas: ellas constituyen un corpus de prescripciones sobre la negación o la afirmación de la justicia social.

En las secciones subsiguientes, describo los fundamentos del Estado constitucional, conjugación en la que adelanto el rol de la igualdad como línea rectora. A continuación, presento una serie de criterios sobre la igualdad en el propio cuerpo normativo del sistema de la Constitución federal de la Argentina (en adelante, CF). Este panorama se integra con la mostración de un relativo fracaso de las enunciaciones normativas sobre el proceso de la igualdad constitucional, actualmente en vigor, en especial, por su insuficiencia. Sin adelantar la conclusión, normativamente, en materia de justicia social, el problema lo constituye más la ausencia de reglas, es decir, la «laguna», antes que la segura y correspon-

Ignacio Bonfiglio (investigador responsable), Buenos Aires, UCA-ODSA, marzo de 2016, disponible en http://www.uca.edu.ar/uca/common/grupo68/files/2016-Obs-Informe-Pobreza-Multidimensional-2010-2015.pdf, consultado el 3/9/2016.

9 Chomsky, Noam, The Prosperous Few and the Restless Many, The Real Story Series, Berkeley, CA, Odonian Press, 1993, disponible en https://chomsky.info/prosperous01/, consultado el 3/9/2016; del mismo autor, «Pocos prósperos, muchos descontentos», en Cómo funciona el mundo: Conversaciones con David Barsamian, Buenos Aires, Katz-Capital Intelectual, 2015, p. 91.

${ }^{10}$ Boввіо, Norberto, Igualdad y libertad, Barcelona, Paidós Ibérica, 1993, p. 93.

11 Alberdi, Juan Bautista, op. cit, p. 23.

12 Instituto Nacional de Estadística y Censos, Estimaciones y proyecciones de población 2010-2040: Total del país, Ciudad Autónoma de Buenos Aires, Instituto Nacional de Estadística y Censos - INDEC, 2013, p. 28, disponible en http://www.indec.mecon.ar/nuevaweb/cuadros/2/ proyeccionesyestimaciones_nac_2010_2040.pdf, consultado el 3/9/2016. 
diente ineficacia de las vigentes. Luego elaboro un Prospectus sobre política constitucional que, llegado el momento constituyente, podría legitimar la extirpación del mal, esto es, erradicar la pobreza.

Advierto que el ámbito de comprensión se dedica a dimensiones del principio de igualdad en la CF. Despliego ideas sobre criterios que juzgo eminentes del principio constitucional, no en todas sus prescripciones regulativas ${ }^{13}$, y sin evaluar las fuentes del Derecho Internacional de los Derechos Humanos (DIDH) con jerarquía constitucional ${ }^{14}$, ni considerar a las legales — por razones de espacio-. En el discurso predomina el enfoque normativo, dado que el objeto de estudio - ora en la descripción, ora en la prescripción — son prevalentemente normas.

\section{ESTADO, CONSTITUCIÓN E IGUALDAD}

El Estado, en América Latina, debiera ser la casa común de sus ciudadanos, cuya soberanía $^{15}$ resulta inherente e indiscutida, por la definición que ejercen la mayoría de sus respectivas «escrituras laicas» ${ }^{16}$. La máxima y libre instancia de asociación política de los ciudadanos debiera integrarse con cuatro elementos: un territorio, su población, el poder y su constitución. Los Estados soberanos de América Latina asumen una constitución republicana para disponer su fundamento ${ }^{17}$. La constitución captada de este modo, como cuarto elemento estatal, significa un «programa» ${ }^{18}$ que se asume, desde luego, como afirmación capital.

13 Así, por ejemplo, no resulta objeto de tratamiento la admisibilidad de todos los habitantes en los empleos sin otra condición que la idoneidad; tampoco, la determinación constitucional de que la igualdad es la base del impuesto y de las cargas públicas. Ambas ordenaciones se encuentran prescritas en el artículo 16 de la CF.

14 Sobre el particular, ver las menciones en torno al catálogo de reglas sobre igualdad constitucionalizadas del DIDH (sección II y sección III. C), que se escogen paradigmas.

15 Artículo 33, CF: «Las declaraciones, derechos y garantías que enumera la Constitución no serán entendidos como negación de otros derechos y garantías no enumerados; pero que nacen del principio de la soberanía del pueblo y de la forma republicana de gobierno».

16 Se parafrasea a Diego Valadés, según su feliz acuñación «Una Constitución... también es el libro laico de un pueblo» (VALADÉs, Diego, «¿Qué hacer con la Constitución?», en Reforma, México, 2/2/2016).

17 La materia ha sido estudiada y se remite en homenaje a la brevedad, a FERrEYrA, Raúl Gustavo, «Manifiesto sobre el Estado constitucional. Reglas fundamentales sobre raigambre y justificación de la comunidad estatal», 1. " parte, Revista de Derecho Público, $\mathrm{n}^{\circ}$ 10, Presidencia de la Nación, Ministerio de Justicia y Derechos Humanos, 2015, pp. 37-124 (Id SAIJ: DACF150418); ídem, 2. ${ }^{a}$ parte, Revista de Derecho Público, n. ${ }^{\circ} 11$, Presidencia de la Nación, Ministerio de Justicia y Derechos Humanos, 2015, pp. 109-182 (Id SAIJ: DACF160051).

18 Peter Häberle, en 1982, anunció su tesis, pieza a pieza, en Verfassungslebre als Kulturwissenschaft («la Constitución como cultura»). La tesis se reitera en «La constitución en el contexto», 
Es sabido que la constitución puede aislarse para su estudio dogmático. Además de su enfoque interno, también existe un enfoque o comprensión externa: el propio modo en que la constitución fundamenta al mundo propiciado por los otros tres elementos del Estado, o el Estado a secas. La fundamentación constitucional del Estado puede cumplirse por intermedio de cuatro reglas de realización progresiva: subordinación, variación, distinción y acción de los derechos fundamentales, que poseen diferente contenido ${ }^{19}$.

La regla sobre la acción de los derechos fundamentales significa que, con su inserción y despliegue en las constituciones, éstos deben realizar una regulación donde se los concibe como derechos subjetivos, pero también como reglas objetivas del sistema; es decir, en este último caso, líneas determinantes de acción que deberían asegurar un uso correcto de la fuerza estatal. En este sentido, la gramática sobre la regla respecto de la acción de los derechos fundamentales conjuga dos escenarios: uno, en el que cada uno de sus derechos están llamados a cumplir un papel directivo del orden jurídico, esto es, la finalidad del poder constituyente para la reglamentación propia de la fuerza estatal; otro, en el que se desempeñan como derechos subjetivos fundamentales. Desde esta perspectiva teórica, los derechos fundamentales son «reglas directivas» — un mapa indispensable, insustituible y orientador para el ejercicio del poder del Estado-y reglas subjetivas o contenidos de un derecho subjetivo.

En este estudio dedicado a la igualdad, uno de los despliegues de la regla sobre la acción de los derechos fundamentales prevalece su consideración como directiva o «norma de principio» ${ }^{20}$, que, bajo cualquier denominación, ciertamente se presenta como una de las condiciones para la paz relativa de una comunidad determinada. La CF contiene una descripción del estado de cosas mencionado, es decir, un estado de cosas deseado por el legislador constituyente sobre los derechos fundamentales. En particular, estas prescripciones se encuentran en la Primera Parte, en su Capítulo Primero: «Declaraciones, derechos y garantías»; en su Capítulo Segundo: «Nuevos Derechos y Garantías»; y en la Segunda Parte, en su Título Primero, Sección Primera, Capítulo Cuarto: «Atribuciones del

AIJC, CEPC, Madrid, n. ${ }^{\circ}$ 7, 2003, pp. 223-245. Adviértase que en este escrito resuelvo deslizar a la constitución como un «cuarto elemento», simplemente, sin ahondar en la inherente proyección «cultural» de la tesis del profesor alemán para nuestro «contexto» latinoamericano.

19 V. Ferreyra, Raúl Gustavo, «Manifiesto sobre el Estado constitucional...», op. cit.

${ }^{20}$ Guastini, Riccardo, «Breve lección sobre la igualdad», Eunomía. Revista en Cultura de la Legalidad, n. ${ }^{\circ}$, Madrid, 2013, pp. 33-41. 
Congreso», instrumentos del DIDH con jerarquía constitucional, artículo 75, inc. $\left.22^{21}\right)$.

En el cuerpo de la CF se reglamentan los siguientes derechos: 1) a la vida, 2) de libertad, 3) de igualdad, 4) políticos, 5) de propiedad «sin contemplar su inherente función social», 6) sociales, 7) de incidencia colectiva y 8) el contrato generacional ambiental. A esta composición de ocho voces se unen, con igual jerarquía constitucional, los «derechos no enumerados» y también aquellos cuya nomenclatura yace en los catorce instrumentos ${ }^{22}$ que gozan de la mayor estatura jurídica en la Argentina ${ }^{23}$. Unos (el «noneto» descrito en la CF) y los otros (descritos en los instrumentos internacionales sobre Derechos humanos que gozan

${ }^{21}$ Por intermedio de la reforma constitucional de 1994 se dispuso en el artículo 75, inc. 22: «... Corresponde al Congreso (...) inc. 22: Aprobar o desechar tratados concluidos con las demás naciones y con las organizaciones internacionales y los concordatos con la Santa Sede. Los tratados y concordatos tienen jerarquía superior a las leyes. La Declaración Americana de los Derechos y Deberes del Hombre; la Declaración Universal de Derechos Humanos; la Convención Americana sobre Derechos Humanos; el Pacto Internacional de Derechos Económicos, Sociales y Culturales; el Pacto Internacional de Derechos Civiles y Políticos y su Protocolo Facultativo; la Convención sobre la Prevención y la Sanción del Delito de Genocidio; la Convención Internacional sobre la Eliminación de todas las Formas de Discriminación Racial; la Convención sobre la Eliminación de todas las Formas de Discriminación contra la Mujer; la Convención contra la Tortura y otros Tratos o Penas Crueles, Inhumanos o Degradantes; la Convención sobre los Derechos del Niño; en las condiciones de su vigencia, tienen jerarquía constitucional, no derogan artículo alguno de la primera parte de esta Constitución y deben entenderse complementarios de los derechos y garantías por ella reconocidos. Sólo podrán ser denunciados, en su caso, por el Poder Ejecutivo nacional, previa aprobación de las dos terceras partes de la totalidad de los miembros de cada Cámara. Los demás tratados y convenciones sobre derechos humanos, luego de ser aprobados por el Congreso, requerirán del voto de las dos terceras partes de la totalidad de los miembros de cada Cámara para gozar de la jerarquía constitucional».

En 1997 se otorgó jerarquía constitucional a la Convención Interamericana sobre Desaparición Forzada de Personas. En 2003, semejante jerarquía a la Convención sobre la Imprescriptibilidad de los Crímenes de Guerra y de los Crímenes de Lesa Humanidad. Por último, en 2014 se dispuso otorgar jerarquía constitucional a la Convención sobre los Derechos de las Personas con Discapacidad.

${ }^{22}$ Ver su detalle en la nota al pie que antecede.

${ }^{23}$ La Declaración Americana de los Derechos y Deberes del Hombre (Preámbulo; arts. II y XII a XVII; XXIX, XXIII y XXXV); Declaración Universal de Derechos Humanos (Preámbulo; arts. 1, 2, 4, 7, 10, 21, 23, 25, 26 y 28); Convención Americana sobre Derechos Humanos (Preámbulo; arts. 1, 2, 6, 8, 13, 17, 23, 24 y 26). El Pacto Internacional de Derechos Civiles y Políticos (Preámbulo; arts. 1.2 2, 2, 3, 8, 14, 20, 24, 26 y 27). La Convención Internacional sobre la Eliminación de todas las formas de Discriminación Racial (arts. 1 a 7). La Convención sobre la Eliminación de todas las formas de Discriminación contra la Mujer (arts. 1 a 16). La Convención contra la Tortura y otros Tratos o Penas Crueles, Inhumanos o Degradantes (arts. 1 y 2). La Convención sobre los Derechos del Niño (arts. 1 a 4, 30 y 31). La Convención sobre los Derechos de las Per- 
de jerarquía constitucional, en las condiciones de su vigencia) congloban un nuevo sistema, el sistema de la CF. En su conjunto, intentan justificar el accionar del Estado y el de los ciudadanos entre sí.

Las piezas sobre derechos fundamentales pueden ser simplificadas o quedar resumidas en la majestuosa invención de 1789: libertad, igualdad y fraternidad. Allí se creó, con naturaleza positiva y sin abstracciones, la «literatura universal» 24 sobre los derechos fundamentales. Más allá de virtuosas clasificaciones, la traza sobre derechos fundamentales, 227 años después aún reposa en la célebre trilogía, porque cada generación contemporánea es beneficiaria de todos los instantes de 1789.

El hecho de que la constitución, con sus fundamentos, arraigue y justifique al Estado no significa que dominará a la persistente desigualdad. Porque se puede legislar con ligereza, en cuyo caso sus normas serán ineficaces. Sin embargo, también la inefectividad puede provenir de la indolencia de los servidores públicos. Reconocer la insuficiencia de las reglas sobre igualdad comprueba la existencia de un problema: un vacío en el Derecho constitucionalizado que la teoría podría rellenar. Los problemas constitucionales, además de su propia entereza y hechura en el ámbito del saber dogmático, son paralelamente un problema político, por lo que inciden en la ordenación de la sociedad. Por lo tanto, la teoría normativa debería enfrentarlos, aun con el riesgo del pálido desenfreno, languidez o utopía de sus proposiciones. En consecuencia, cuanto pueda realizar el instrumento constitucional por la igualdad de sus habitantes — apoyado por la teoría - resulta un asunto vital, en razón de la naturaleza fundamental que constituyen sus reglas para el bienestar general y ciudadano.

\section{CRITERIOS SOBRE LA IGUALDAD}

El Estado argentino encuentra fundamento en la escritura más antigua de las latinoamericanas en vigencia. El artificio fue inventado en 1853 e impuesto desde entonces con reformas en 1866, 1898, 1957 y 1994. Nació a mediados del siglo xix en el marco de un débil, fragmentado y casi inexistente acuerdo comunitario; una oligarquía fue la que impuso un orden en su beneficio.

Desde 1853 el Preámbulo enuncia, de modo invariable, seis objetivos: «constituir la unión nacional», «afianzar la justicia», «consolidar la paz interior»,

sonas con Discapacidad (arts. 1, 3 a 7, 9, 12, 16 y 17). El Pacto Internacional de Derechos Económicos, Sociales y Culturales es individualizado más adelante, en la sección III. C.

24 HäBERLE, Peter, Libertad, igualdad, fraternidad: 1789 como historia, actualidad y futuro del Estado constitucional, Madrid, Trotta, 1998, p. 34. 
«proveer a la defensa común», «promover el bienestar general» y «asegurar los beneficios de la libertad». Ahora bien, es preciso observar que el objetivo de la paz constituye el fin mínimo del orden jurídico que requiere de la libertad y de la igualdad («bienestar general» ${ }^{25}$ ) como condiciones necesarias.

Tal como anticipé en la sección I, mantengo la utopía rousseauniana de que el «pacto fundamental» (la «constitución») sustituya con una igualdad «social» lo que la naturaleza haya establecido de desigualdad física entre los hombres, para que así quienes sean desiguales en fuerza o en talento se conviertan en iguales por convención y Derecho. Además, con cordura inigualable, Jean-Jacques Rousseau advirtió que, bajo los malos gobiernos, esta igualdad no era más que aparente e ilusoria, porque sirve para mantener al pobre en su miseria y al rico en su usurpación. Desde su enfoque, las leyes son siempre útiles a los que poseen y perjudiciales a los que no tienen nada. Por ello, el Estado social sólo es ventajoso para los hombres si «todos poseen algo»y ninguno de ellos tiene demasiado $^{26}$.

El principio de igualdad, tal como planteo más adelante, es una regla constitucional cuya naturaleza convencional puede tener diferentes dimensiones en su regulación específica. El principio de igualdad nace y se desarrolla porque la desigualdad entre los hombres es un verdadero mal. La igualdad, en tanto convención humana, daría la ilusión de una convivencia pacífica, ya que cada uno sería respetado y tratado con fundamento en la indisponible y dignísima identidad que hace de cada hombre un ser único, irrepetible, singular e insustituible. Sin embargo, no alcanza ser tratado igualmente con abierto y fundamental respeto a nuestras diferencias por el orden jurídico, aun con el escrutinio más riguroso. También constituye un horizonte de proyección la eliminación o reducción de la desigualdad social a la que, en general, no se le ha prestado mayor atención.

Hoy, en la Argentina, se aprecia la serenidad de una paz relativa, luego del genocidio despiadado contra los indígenas durante el siglo xIX, en la denominada «Conquista del Desierto», y el perpetrado por el terrorismo de Estado a manos de una dictadura militar — apoyada por civiles - durante el siglo Xx (24/3/1976-10/12/1983). Transcurridos más de 160 años desde la fundación

25 La CSJN, integrada por conjueces, dispuso que el objetivo preeminente, según determina el preámbulo, es lograr el «bienestar general», la justicia en su más alta expresión, esto es, la justicia social, cuyo contenido actual consiste en ordenar la actividad entre los miembros de la comunidad y los recursos con que ésta cuenta con vistas a lograr que todos y cada uno de ellos participen de los bienes materiales y espirituales de la civilización (in re «Miguel A. Bercaitz», CSJN, 13/9/1974, Fallos 289:430).

26 Rousseau, Jean-J., Du contrat social ou Principes du Droit Politique, París, Flammarion, 2001, p. 60. 
constituyente de la Argentina, sus determinaciones abstractas, amén de sus reformas, han convertido a la $\mathrm{CF}$ en un bien comunitario indispensable. Tal «naturaleza colectiva» ${ }^{27}$ de la CF como bien jurídico la convierte en la norma procesal más distinguida para la concreción, desarrollo y organización de una paz objetiva y relativa. «Todos sus [habitantes] poseen algo»: la paz; sin embargo, no se han producido sucesivas aproximaciones para eliminar o amortiguar la desigualdad social en el resto de los bienes. No es una revelación secreta: existe un desequilibrio cuya corrección corresponde a gobernantes y también a sus ciudadanos.

La desigualdad social es una deuda pendiente que martiriza el presente y configura un futuro lleno de desventajas para la mayoría de sus habitantes. Mundialmente, confrontan dos modelos de comunidad que se intentan configurar y pugnan, la mayoría de las veces, entre sí: una comunidad incluyente, con ciudadanos, cuyo horizonte de proyección lo constituye determinada igualación; y otra excluyente, con una ciudadanía de baja o nula intensidad para los desposeídos y de alta intensidad para aquellos que disfrutan del conjunto de las ventajas ${ }^{28}$. Esta situación se observa en la Argentina desde hace muchos años. Nuestro país no dispone de un criterio de justicia social que, con fundamento constitucional, concrete el trato igualitario a los iguales y el trato desigual a los desiguales. Casi el $60 \%$ de sus habitantes no debería encontrarse - como se encuentra- en situación de pobreza o vulnerabilidad social.

\section{A. Inventario sobre la igualdad constitucional en la Argentina}

La libertad es el gen de todos los derechos fundamentales, porque todos los derechos derivan de la libertad o la libertad es su fuente de nutrición. La igualdad en la libertad es la libertad jurídica que capta la CF en su artículo 19. En rigor, no se trata de una constitución igualitaria sino liberal, en el sentido de que su finalidad originaria es la expansión y protección de la libertad. Los constituyentes, en 1853, edificaron un Estado liberal, con intervención mínima en orden al reparto y adquisición de bienes en la economía.

Si bien desde luego no rechazo el igualitarismo, la CF, en su texto y edición príncipe, simplemente iguala a «algunos en alguna cosa»: paz y libertad. Esta comprensión condice con una versión no igualitaria de la comunidad en su conjunto, desde la que se encuentra bien lejos de una posición igualitaria y utópica,

27 Bidart Campos, Germán J., La constitución que dura, Buenos Aires, Ediar, 2004, p. 22.

28 V. Zaffaroni, E. Raúl, El Derecho en la fase superior del colonialismo, Buenos Aires, Ediciones Madres de Plaza de Mayo, 2015, p. 49. 
determinada, por ejemplo, por una «igualdad entre todos en todo». Interpretar que la CF fuese igualitaria no coincidiría con su normatividad específica. Juzgo desgraciada la modesta referencia al igualitarismo. Los personajes principales de la «novela constitucional», los ciudadanos, se orientan a un mundo jurídico básico en el que cada uno de ellos queda asignado a su suerte, antes que a sus necesidades.

Jurídicamente, la igualdad entraña una singular relación entre los individuos, cuyo sumario o contenido puede tener los más diversos elementos. Por tal razón, en la escritura constitucional el contenido de la igualdad siempre requiere la determinación mínima sobre dos inquietudes preliminares: ¿igualdad entre quiénes? e ¿igualdad en qué? ${ }^{29}$ Sin la estipulación de relaciones formales, sin la determinación de un contexto, difícilmente pueda predicarse, en abstracto, sobre la igualdad. Así, la petición por la igualdad significa postular sobre la naturaleza y contenido de las relaciones que deberían constitucionalizarse entre los diferentes individuos que constituyen la comunidad. Porque los seres humanos somos de hecho desiguales, la igualdad es un bien para los componentes individuales de una totalidad comunitaria.

En las constituciones la igualdad se instituye por, al menos, tres especies de normas: ante la ley, de oportunidades y sustancial. Esto es apenas una tipología, dado que, en tanto hecho cultural, cada uno de estos tipos se encuentra separado por un abismo, muchas veces insalvable, $\mathrm{y}$, al mismo tiempo, al ser individuados encierran dentro sí mismos un determinado grado de igualdad. Llamo la atención sobre el «tipo»; así, en virtud de la «igualdad frente al Derecho», tanto el rico como el pobre serán tratados con la misma regla. Esta isonomía ${ }^{30}$ basta para mantenerlos en la órbita de sus condiciones existenciales, pero es abiertamente insuficiente para proveer alguna aproximación a una igualdad sustancial sobre algunos bienes objeto de reparto o distribución comunitaria. Gracias a o por influjo de la isonomía, el rico seguirá disfrutando de toda su riqueza y el pobre hará lo que pueda para vivir su pobreza material. Por su parte, los «grados de la isonomía» permiten observar un ejercicio cuidado y riguroso respecto del tratamiento de los individuos más y menos aventajados que viven en la comunidad, en el igual trato ante la ley que cada uno de ellos debería recibir.

29 BobBio, Norberto, Igualdad y libertad, op. cit., p. 54.

30 Recuérdese, sobre el particular, un magnífico texto de EuRípIDEs: «... Nada hay más enemigo de un Estado que el tirano. Pues, para empezar, no existen leyes de la comunidad y domina sólo uno que tiene la ley bajo su arbitrio. Y esto no es igualitario. Cuando las leyes están escritas, tanto el pobre como el rico tienen una justicia igualitaria. El débil puede contestar al poderoso con las mismas palabras si le insulta; vence el inferior al superior si tiene a su lado la justicia» (Tragedias, II, Suplicantes, Madrid, Gredos, 2008, p. 41). 


\section{B. Igualdad ante la ley}

Desde 1853 la ley fundamental de la Argentina, en su artículo 16, recoge la primera de las especies: «Todos sus habitantes son iguales ante la ley». Por su parte, en el artículo 15 se abolió la esclavitud y se criminalizó la compraventa de personas, con propiedad terminante y desde la positividad constitucional ${ }^{31}$. La directiva «igualdad ante la ley» ${ }^{32}$ configura una aserción enérgica; en principio, pareciera que dirigida al legislador constituido. Sin embargo, cuando se escarba, la directiva debe ser extendida frente a todo el aparato del Estado; no debe quedar restringida a la configuración del legislador, ya que el Derecho es el prototipo del producto estatal. También se debe extender a la realización jurídica ante la administración y ante la jurisdicción; al igual que entre particulares, en la medida de lo razonable ${ }^{33}$.

Resulta más adecuada la siguiente afirmación: «igualdad ante el Derecho». Pese a que se trata de una ordenación dirigida a regir entre todos, los servidores públicos (Poder Ejecutivo, legisladores y jueces) son quienes, a menudo, se encuentran irracionalmente dispuestos a discriminar sin justificación o sin ejercer un elemental escrutinio riguroso. En suma, el Derecho, instrumento para la ordenación de la comunidad, por definición instituida para la configuración de una República, resultará igual para todos los habitantes. Por ello, quedan discriminadas, por inconstitucionales, las distinciones efectuadas o no eliminadas por cualquier servidor público, sin fundamentos objetivados en el Derecho o que carezcan de tales en el propio orden jurídico sobre determinación de la conducta humana.

La igualdad en el Derecho implica, en principio, que en cada ser humano se ha de conferir reconocimiento a un sujeto jurídico con semejante e inherente titularidad y capacidad. El Derecho es, originalmente, igual para todos, siempre

31 Artículo 15, CF: «En la Nación Argentina no hay esclavos: los pocos que hoy existen quedan libres desde la jura de esta Constitución [9 de julio de 1853]; y una ley especial reglará las indemnizaciones a que dé lugar esta declaración. Todo contrato de compra y venta de personas es un crimen de que serán responsables los que lo celebrasen, y el escribano o funcionario que lo autorice. Y los esclavos que de cualquier modo se introduzcan quedan libres por el solo hecho de pisar el territorio de la República».

32 Se observa, más adelante, que la CF, con el DDHH de jerarquía constitucional, congloba el sistema de la CF. El artículo 24 de la Convención Americana sobre Derechos Humanos, con jerarquía constitucional, por ejemplo, contiene una prescripción más elocuente y abarcadora: «Todas las personas son iguales ante la ley. En consecuencia, tienen derecho, sin discriminación, a igual protección de la ley».

33 V. Rosatti, Horacio D., Tratado de Derecho constitucional, t. I, Buenos Aires, Rubinzal Culzoni, 2010, p. 186. 
que no exista una razonada fuente para discriminar. Se trata, sin dudas, de una simplificada igualdad excluyente de cualquier discriminación no objetivada en el orden jurídico ni justificada, aunque restringida, ya que comporta «igualdad» de trato dentro del propio Derecho objetivado ${ }^{34}$.

La prohibición subyace detrás del escenario del artículo 16 de la CF: tratar de modo desigual ante igualdad de condiciones jurídicas. No se anula la posibilidad de formular distinciones razonables; tampoco significa que el Derecho debe considerarnos del mismo modo, si no estamos en semejantes condiciones. Será natural que el Derecho haga distinciones Eso significa que los individuos emplazados en situaciones semejantes, en iguales circunstancias, que se encuentren dentro de un marco semejante, deben ser, imperativamente, tratados del mismo modo. Si el Derecho contempla en forma distinta situaciones que son iguales objetivamente, hay razones suficientes para peticionar la inconstitucionalidad, porque constituye una distinción arbitraria, violatoria del artículo 16 de la $\mathrm{CF}^{35}$.

La isonomía tiende a que se realice un trato semejante, fundamentalmente, por parte del Derecho del Estado. Puesto el Derecho en el mundo - en concreto, la constitución de una República-, los hombres deben ser tratados por igual y su destino respecto del trato igualitario debe ser semejante. Siempre que se encuentren en semejantes condiciones, el principio elimina el tratamiento irrazonablemente distintos entre ellos. Una república sólo puede ser una república de seres humanos iguales en los términos dichos. Sin embargo, la igualdad ante el Derecho no resuelve la igualdad en las oportunidades sociales que podría tener el individuo. Tampoco la justicia social. Quienes dominan el aparato productivo de un Estado, por regla, tendrán mayores posibilidades para generar las normas del Derecho; también, por lo general, en su propio beneficio o provecho insolidario. La isonomía, por lo tanto, indicará una igualdad ante las normas jurídicas producidas en el Estado constitucional y que se deben acatar, pero en un marco de desigualdad y exclusión comunitaria creciente, por una razón evidente: en

34 La Corte Suprema de Justicia de la Argentina dictó su primer pronunciamiento en 1863. En materia de igualdad ante la ley, doce años más tarde, al confirmar una decisión de la justicia federal, sus jueces expresaron en la causa «Olivar»: «... El principio de la igualdad de todas las personas ante la ley, según la ciencia y el espíritu de nuestra Constitución, no es otra cosa que el derecho a que no se establezcan excepciones o privilegios que excluyan a unos de lo que se concede a otros en iguales circunstancias, de donde se sigue forzosamente que la verdadera igualdad consiste en aplicar en los casos ocurrentes la ley según las diferencias constitutivas de ellos, y que cualquiera otra inteligencia o acepción de este derecho es contraria a su propia naturaleza o interés social» (Fallos 16:118, con las firmas de S. del Carril, F. Delgado, J. Barros Pazos, J. B. Gorostiaga y J. Domínguez, 1/5/1875).

35 In re «Martínez», CSJN, 6/6/1989, Fallos 312:826. 
este caso, la desigualdad social delimita la liberación del aparato estatal, pero no la sumisión al aparato productor de riquezas.

Por las razones expuestas, no trato todas las manifestaciones constitucionales de la igualdad. Aquí sólo menciono que en el mismo artículo 16 de la CF se han eliminado de la República las prerrogativas de sangre y de nacimiento, los títulos de nobleza y los fueros personales, aunque yace implícito que «no se dará efecto alguno a los otorgados por cualquier otro país». En este último aspecto, vale destacar el mérito del pensamiento original expresado en la Constitución Política de los Estados Unidos Mexicanos de 1917 (en adelante, CPEUM 1917), en su artículo 12, que sí fue un paso más allá36. En el artículo 16 de la CF se prescribe, además, que todos los habitantes son «admisibles en los empleos sin otra condición que la idoneidad», y que la «igualdad es la base del impuesto y de las cargas públicas» ${ }^{37}$.

\section{Igualdad de oportunidades}

Constituye la segunda de las especies del género «igualdad». Por su intermedio se intenta emplazar en posiciones semejantes a determinados individuos de una comunidad respecto de bienes significativos. Se trata de una igualdad de puntos de partida o puestos de arranque de determinada competencia respecto de bienes. Los participantes de este «juego comunitario» sobre un — concreto o abstracto- reparto de bienes tendrían semejante chance porque, por definición constitucional, «todos» los que participen lo harían desde la misma línea de comienzo. Desde luego, la enorme flaqueza del principio de igualdad de oportunidades radica en el hecho de que, por regla, no se determinan, a su vez, otras normas indispensables para considerar la igualdad real y efectiva en las propias posiciones de partida. Hay igualdad de oportunidades respecto del juego, pero no existen reglas que afirmen o posicionen a los desiguales para concretar, sin discriminaciones, el mismísimo comienzo de la competencia. Aunque la oportunidad será la misma en la competencia, ¿cómo se accede a la mismísima oportunidad?

36 Véase artículo 12, CPEUM: «En los Estados Unidos Mexicanos no se concederán títulos de nobleza, ni prerrogativas y honores hereditarios, ni se dará efecto alguno a los otorgados por cualquier otro país».

37 Sin perjuicio de lo argumentado en la sección I «Advertencia», un brevísimo apunte se puede leer, más adelante, en el punto IV. C «Entreacto. Tributación y dominio de los recursos naturales», «Primero». 
La igualdad de oportunidades, en forma parcial, recién se introduce con la reforma constitucional de $1949^{38}$, en cuyo Preámbulo se instituyó la «irrevocable decisión de constituir una Nación socialmente justa». La ley fundamental de 1949 ya no existe, pero en sus palabras se asentaron conmovedores aspectos de su presente y, sobre todo, un testimonio para el porvenir del constitucionalismo social ${ }^{39}$.

Quizá, por la consistente razón de que nada ni nadie puede vivir eternamente, la cruda desigualdad social prohijada por la CF, según su texto de 1853-60, tuvo un paliativo en 1957. Entonces la expansión constitucional que se produjo, por la incorporación del artículo 14 bis, sensibilizó aspectos de la desigualdad de hecho e introdujo un papel más activo del Estado, en particular sobre el contrato de trabajo y la seguridad social En su primer apartado se establece:

El trabajo en sus diversas formas gozará de la protección de las leyes, las que asegurarán al trabajador (...) condiciones dignas y equitativas de labor, (...) retribución justa; (...) igual remuneración por igual tarea» (...) Łył participación en las ganancias de las empresas, con control de la producción y colaboración en la dirección.

En la CF 1853-60, el trabajo, actividad decisiva en la vida del individuo y en el desarrollo de la comunidad, fue contemplado desde la natural desigualdad de las partes contratantes y, por ello, librado a la imposición del patrono. La ausencia de normas protectoras del trabajo fue juzgada, con acierto, como una verdadera y genuina imperfección ${ }^{40}$ de la CF de 1853 , a la que se debía suministrar un remedio suficiente.

En el segundo apartado adquiere ciudadanía el derecho a convenios colectivos de trabajos. Más adelante, en el tercer y último apartado del artículo 14 bis, se

${ }^{38}$ Básicamente, por intermedio de esta variación se constitucionalizó en la Primera Parte «Principios fundamentales», Cap. III (Derechos del trabajador, de la familia, de la ancianidad y de la educación y la cultura) y Cap. IV (La función social de la propiedad, el capital y actividad económica). Sobre bibliografía vasta, puede leerse «Diálogo sobre la Constitución de 1949. Entrevista al Dr. E. Raúl Zaffaroni, Revista de Derecho Público», n. ${ }^{\circ}$ 11, Presidencia de la Nación, Ministerio de Justicia y Derechos Humanos, 2015, pp. 284-307.

39 En 16/9/1955 fueron derrocadas las autoridades constitucionalmente elegidas por un golpe militar apoyado por civiles. El 27/4/1956, el gobierno provisional «de la Nación Argentina, en ejercicio de sus poderes revolucionarios", por intermedio de una proclama con fuerza obligatoria, declaró vigente la Constitución federal sancionada en 1853, con las reformas de 1860, 1866 y 1898 , y la exclusión de la de 1949, sin perjuicio de los actos y procedimientos que hubieren quedado definitivamente concluidos con anterioridad al 16/9/1955.

40 Sánchez Viamonte, Carlos, Los defectos sociales de la Constitución de 1853, Buenos Aires, Claridad, 1933, pp. 57-59. 
define que «El Estado otorgará los beneficios de la seguridad social, que tendrá carácter de integral e irrenunciable». Además, se remite su desarrollo a la «ley», «... que establecerá: el seguro social obligatorio (...), jubilaciones y pensiones móviles; la protección integral de la familia; la defensa del bien de familia; la compensación económica familiar» y el acceso a una vivienda digna».

Las reglas consagradas en el artículo 14 bis constituyen un protocolo de corrección, bien limitado, respecto de la CF de 1853, y dieron cierta cobertura a una ansiosa inseguridad. No hay que obnubilarse con la superficie del artículo 14 bis. Sus reglas, cargadas de ilustradas idealidades, distan de ser referidas como una teoría de la tributación óptima o, todavía más lejos, del rol global del Estado en la ordenación de los factores de la economía. No significan un ataque certero sobre las causas de la injusta distribución de la riqueza ni respecto de las peligrosas consecuencias que se derivan de la vulnerabilidad y la pobreza de los individuos en la comunidad. No es, en verdad, una fatalidad de la escritura del artículo 14 bis, porque no existen la obra maestra, ni el plan de acción genuino que puedan derrotar para siempre a las tempestades de la exclusión social.

La Constitución reformada en 1994 ha intentado remediar la soledad del significante introducido en 1957. Se insinúa una nueva dimensión para la igualdad, bajo la influencia de un nuevo papel para el Estado. Para forzar cierto emparejamiento social de los individuos. Así, en el artículo 75, inc. 2 (Atribuciones del Congreso), se establece lo siguiente:

... Una ley convenio, sobre la base de acuerdos entre la Nación y las provincias, instituirá regímenes de coparticipación de estas contribuciones, garantizando la automaticidad en la remisión de los fondos.

La distribución entre la Nación, las provincias y la ciudad de Buenos Aires y entre éstas, se efectuará en relación directa a las competencias, servicios y funciones de cada una de ellas contemplando criterios objetivos de reparto; será equitativa, solidaria y dará prioridad al logro de un grado equivalente de desarrollo, calidad de vida e igualdad de oportunidades en todo el territorio nacional.

También en el artículo 75, inc. 23, se atribuye al Congreso la siguiente competencia:

... legislar y promover medidas de acción positiva que garanticen la igualdad real de oportunidades y de trato, y el pleno goce y ejercicio de los derechos reconocidos por esta Constitución y por los tratados internacionales vigentes sobre derechos humanos, en particular respecto de los niños, las mujeres, los ancianos y las personas con discapacidad.

Dictar un régimen de seguridad social especial e integral en protección del niño en situación de desamparo, desde el embarazo hasta la finalización del pe- 
ríodo de enseñanza elemental, y de la madre durante el embarazo y el tiempo de lactancia.

En el inc. 19 del artículo 75 citado se confiere competencia al Congreso federal para sancionar:

... leyes de organización y de base de la educación que consoliden la unidad nacional respetando las particularidades provinciales y locales; que aseguren la responsabilidad indelegable del Estado, la participación de la familia y la sociedad, la promoción de los valores democráticos y la igualdad de oportunidades y posibilidades sin discriminación alguna; y que garanticen los principios de gratuidad y equidad de la educación pública estatal y la autonomía y autarquía de las universidades nacionales.

En el mismo inciso se prescribe que es una competencia del Congreso:

Proveer lo conducente al desarrollo humano, al progreso económico con justicia social, a la productividad de la economía nacional, a la generación de empleo, a la formación profesional de los trabajadores, a la defensa del valor de la moneda, a la investigación y al desarrollo científico y tecnológico, su difusión y aprovechamiento.

Proveer al crecimiento armónico de la Nación y al poblamiento de su territorio; promover políticas diferenciadas que tiendan a equilibrar el desigual desarrollo relativo de provincias y regiones. Para estas iniciativas, el Senado será Cámara de origen.

El inc. 17 del artículo 75, referido a los pueblos indígenas argentinos, trae un enunciado que hace al reconocimiento de su identidad y también hace a su diferencia, que se yergue como formulación precisa y concreta del derecho a la igualdad de trato y de oportunidades ${ }^{41}$.

Por otra parte, en el artículo 42 se dispone:

Los consumidores y usuarios de bienes y servicios tienen derecho, en la relación de consumo, a la protección de su salud, seguridad e intereses económicos; a una información adecuada y veraz; a la libertad de elección, y a condiciones de trato equitativo y digno.

${ }^{41}$ Artículo 75, inc. 17, CF: «Reconocer la preexistencia étnica y cultural de los pueblos indígenas argentinos. Garantizar el respeto a su identidad y el derecho a una educación bilingüe e intercultural; reconocer la personería jurídica de sus comunidades, y la posesión y propiedad comunitarias de las tierras que tradicionalmente ocupan; y regular la entrega de otras aptas y suficientes para el desarrollo humano; ninguna de ellas será enajenable, transmisible ni susceptible de gravámenes o embargos. Asegurar su participación en la gestión referida a sus recursos naturales y a los demás intereses que los afecten...». 
Las autoridades proveerán a la protección de esos derechos, a la educación para el consumo, a la defensa de la competencia contra toda forma de distorsión de los mercados, al control de los monopolios naturales y legales, al de la calidad y eficiencia de los servicios públicos, y a la constitución de asociaciones de consumidores y de usuarios.

La legislación establecerá procedimientos eficaces para la prevención y solución de conflictos, y los marcos regulatorios de los servicios públicos de competencia nacional, previendo la necesaria participación de las asociaciones de consumidores y usuarios y de las provincias interesadas, en los organismos de control.

En el artículo 37, al referirse a los derechos políticos, se consagra la igualdad real de oportunidades entre varones y mujeres para acceder a cargos electivos y partidarios; allí mismo se prescribe que esa igualdad se ha de garantizar por «acciones positivas en la regulación de los partidos políticos y en el régimen electoral».

Tal como se indica en la sección II, el inc. 22 del artículo 75 está dedicado a los instrumentos internacionales sobre Derechos humanos con jerarquía constitucional; entre los cuales abundan las reglas sobre la igualdad, las minorías y la no discriminación. Cumplo la premisa establecida, más adelante, en la sección I: escojo una de las reglas del DIDH —a la sazón, un confiable paradigma-, que complementa el panorama de la materia regulado por la CF.

Así, en el Pacto Internacional de Derechos Económicos, Sociales y Culturales, por ejemplo, se dispone: a) artículo 2.1 (el compromiso de los Estados «hasta el máximo de los recursos de que disponga», para lograr "progresivamente», por «todos los medios apropiados», la plena efectividad de los derechos que allí se reconocen; b) artículo 4 (el Estado reconoce que, en el ejercicio de los derechos garantizados por el Pacto, éste "podrá someter tales derechos únicamente a limitaciones determinadas por ley, sólo en la medida compatible con la naturaleza de esos derechos y con el exclusivo objeto de promover el bienestar general en una sociedad democrática»).

La igualdad de oportunidades intenta colocar, socialmente, a la mayoría de los individuos en semejantes condiciones para la conquista de bienes relevantes, significativos y que se juzgan provechosos de antemano en el desarrollo de la comunidad. Sin embargo, las precondiciones del juego, que determinarán la igualdad en la posición de partida, no son resueltas, en general, por las reglas de esta naturaleza. En otras palabras, la igualdad de oportunidades resuelve un tratamiento igual en el punto de referencia adoptado como partida para una competición sobre bienes escasos o relevantes, pero no resuelve el hecho de que esos bienes sean distribuidos en un grado de máxima igualación. La igualdad de oportunidades ofrece una mayor respuesta al trato y desarrollo «según las capa- 
cidades» de los individuos; por eso su acento recaerá, incidentalmente, en la satisfacción de la igualdad según las necesidades individuales respectivas.

Las reglas invocadas, quizá todas las reglas de un orden jurídico, deberían quedar captadas por la maravillosa enunciación prescriptiva contenida en el artículo 28 de la Declaración Universal de los Derechos Humanos: «Toda persona tiene derecho a que se establezca un orden social e internacional en el que los derechos y libertades proclamados en esta Declaración se hagan plenamente efectivos».

\section{C.1 Entreacto. Las oportunidades en la Constitución Política de los Estados Unidos Mexicanos de 1917}

La ley fundamental mexicana contenía 136 artículos permanentes y 16 transitorios. Las 136 reglas permanentes se emplazaron en 9 títulos. El título 6 «Del trabajo y la previsión» contenía apenas un artículo, el 123. Sus previsiones normativas ocupan casi un $10 \%$ de la textura constitucional. Un mérito absoluto de los constituyentes mexicanos: nadie, hasta entonces, en la «lengua del Derecho» ${ }^{42}$ de nuestra de América Latina había regulado la cuestión social, en las constituciones, con semejante rigor analítico y solvencia jurídica. Su escritura ha sido un modelo de inspiración constante en sus primeros 100 años, en todo el mundo ${ }^{43}$.

42 VAlADÉs, Diego, La lengua del derecho y el derecho de la lengua, México, Academia Mexicana de la Lengua-UNAM (Instituto de Investigaciones Jurídicas), 2005, pp. 7, 67 y 123.

43 Algunas de las «bases» que deben regir el trabajo de «los obreros, jornaleros, empleados, domésticos y artesanos, y, de una manera general, todo contrato de trabajo», regladas en el artículo 123, CPEUM, en su redacción original de 1917: duración de la jornada máxima; labores insalubres o peligrosas para las mujeres en general y para los jóvenes menores de diez y seis años; prohibición del trabajo de los niños menores de doce años; descanso hebdomadario; licencia por maternidad; periodo de la lactancia; salario mínimo que deberá disfrutar el trabajador; una participación en las utilidades por los trabajadores; pago del salario; horas extras; obligación de los patrones de proporcionar a los trabajadores habitaciones cómodas e higiénicas, escuelas, enfermerías y demás servicios necesarios a la comunidad; accidentes del trabajo y de las enfermedades profesionales; sobre higiene y salubridad en el trabajo; derecho de los obreros y de los empresarios para coaligarse en defensa de sus respectivos intereses, formando sindicatos, asociaciones profesionales, etc.; conciliación y arbitraje; derecho de los obreros y de los patronos a las huelgas y los paros; protección contra el despido sin causa justificada y preferencia de los créditos en favor de los trabajadores por salario o sueldos devengados en el último año y por indemnizaciones; bienes que constituyan el patrimonio de la familia y sociedades cooperativas para la construcción de casas baratas e higiénicas, destinadas a ser adquiridas en propiedad, por los trabajadores en plazos determinados. 


\section{Igualdad sustancial}

En el período 1853-1994 se reglamentó la igualdad ante la ley, con notorio desdén y pasividad del Estado para enfrentar la desigualdad social. Por eso, la CF, en su dimensión originaria sobre la igualdad, no es igualitaria ni se la puede asimilar al «igualitarismo» ${ }^{44}$. Insisto: es igualitaria sólo en referencia a la posición ante el Derecho: todos sus habitantes son iguales en libertad. Sobre esta igualdad determinada por la CF, hasta se edificó una doctrina judicial para dar justificación no igualitaria para los desposeídos ${ }^{45}$. Sin dudas, reprochable ordenación de un estándar desigualitario.

La igualdad suele dividir las aguas de una escritura constitucional porque, en general, sus prescripciones contienen, predominantemente, una orientación hacia determinado progreso. La igualdad, por sí misma, no llena de alegría, pero sus palabras dan crecimiento a un clima positivo, más favorable, inclinado a las ventajas. En la sección III. A he señalado la naturaleza indeterminada o relacional de la igualdad; cuando se trata de bienes materiales, hasta que se defina respecto de qué bienes y entre qué individuos, no es sencillo obtener precisión. En cambio, la igualdad ante el Derecho proporciona la idea respecto de qué relación ha de existir entre los individuos y los servidores públicos con el principal producto del Estado; estrictamente, tal igualdad es una propiedad del orden jurídico que dispone una determinada relación (tratamiento semejante) ante el Derecho. En definitiva, para conservar ese orden jurídico se hace necesario que cada uno de los sujetos que lo acatan o realizan tenga un lugar propio, indivisible e independiente bajo el sol. Por eso, los sujetos son igualados en su relación con el Derecho, cuya producción descansa habitualmente en la hegemonía suficiente del propio poder dominante en la comunidad y en determinado tiempo y espacio.

El mundo del Derecho constitucional fue creado con la relación básica de la igualdad ante el Derecho. Este memorial de la humanidad significa que casi todas las constituciones han sido fertilizadas con su nombre y estilo. La creación de la igualdad ante el Derecho — ante el propio Derecho constitucional del Estadoa medida que fue nombrada, jamás ha sido eliminada de los órdenes jurídicos. Permanecieron las palabras. Y, así, los hombres, con el propósito de mantener día con día la creación originaria de la igualdad, se confesaron entre ellos «igualmente

44 RosatTi, Horacio D., op. cit., p. 167.

45 En el texto constitucional sobre igualdad anclado en el artículo 16, CF: «... No es la nivelación absoluta de los hombres lo que se ha proclamado, aspiración quimérica y contraria a la naturaleza humana, sino su igualdad relativa, propiciada por una legislación tendiente a la protección en lo posible de las desigualdades naturales» (in re «Eugenio Díaz Vélez», CSJN, 20/6/1928, Fallos 151: 359). 
libres». Juzgaron que las brumas o, peor aún, las amenazas o las violaciones de la libertad sólo podían provenir del ente que monopoliza la fuerza, el Estado.

Desde entonces, nos hemos empeñado en fortalecer esa misión igualitaria ante el Derecho. Sin embargo, no ha podido ni siquiera aliviar la ausencia de igualdad con relación a los instrumentos que dispone una economía. La igualdad de oportunidades se construyó como una nueva grandeza, incipiente, para paliar o aventar, tibiamente, la inequidad radical frente al aparato productivo o respecto de otros bienes escasos y deseados en la comunidad.

El discurso de la igualdad de oportunidades no ha derogado ni abolido la desigualdad. Tampoco se espera que la mutile. En verdad, genera expectativas muchas veces razonables, pero sus raíces son restringidas; aunque el propio discurso sostiene un ideal intervencionista del Estado para forzar la equidad en determinadas relaciones, su definición básica lo limita a «situar» en condiciones de competición — se dice «originaria»— al individuo o a los individuos. Sucede que por el mismo hecho de la desigualdad originaria, al comenzar la competición, el menos favorecido tendrá menos posibilidades para nivelar la desigualdad. Corresponde entender el ámbito de la igualdad de oportunidades limitada a lo social.

$¿$ Estamos ante una crisis de la igualdad? Considero que no, porque cuando ingresamos a los ámbitos de sus territorios específicos con determinaciones concretas, la igualdad frente al Derecho muestra su finura y la igualdad de oportunidades enderezada a lo social, semejante blancura. Nunca se dijo ni se podría aducir una espléndida igualdad sustantiva, una igualdad de hecho, una igualdad con relación al aparato productivo con sujeción a los estandartes que vigilan las ciudadelas de la igualdad jurídica o de la igualdad social, respectivamente.

Las doctrinas sobre igualdad sustancial no son un sueño, pero la mayoría de las veces encarnan modelos fáciles de inspirar y prototipos difíciles de satisfacer. Esta igualdad, la sustancial, se distingue de las anteriores: «ante el Derecho»y la «de oportunidades». En este caso, esta igualdad refiere, de hecho, a la relación entre los individuos de una comunidad y los bienes concretos, materiales, de la economía yacentes en la comunidad. El enigma es cómo se distribuirán.

Sin embargo, en el ámbito teórico de la igualdad sustancial, las preguntas se amontonan. Resulta inevitable partir de la naturaleza escasa o reducida de los bienes materiales, cuya distribución se ha de estimular. Caso contrario, si los bienes materiales fuesen exageradamente abundantes, la cuestión no mostraría semejante complejidad. Mencionaré un decálogo de problemas o cuestiones espinosas, muchas de ellas insolubles. Primero, ¿con fundamento en qué criterios se ha de determinar qué es un bien susceptible de reparto y qué bien, por el contrario, es indivisible? Segundo, ¿qué necesidades individuales se han de considerar para la asignación de un bien? Tercero, ¿cómo se hará para distinguir qué necesidades 
y con qué bienes quedarán o serán satisfechas y cuáles seguirán suerte contraria? Cuarto, ¿la reputación de un bien susceptible de distribución se hará según se distingan entre cosas del mundo natural y artefactos del mundo cultural? Quinto, ¿con la distribución del bien termina el proceso igualitario? Sexto, ¿cuál será la relación jurídica entre el bien y el sujeto individual: propiedad comunitaria, posesión, tenencia, permiso de uso o consignación? Séptima, ¿una vez establecida la anterior relación entre el bien y el sujeto, los hombres permanecerán y desarrollarán esa misma relación o, acaso, la cambiarán? Octavo, ¿cómo se repartirán los bienes: a cada uno en partes iguales o a cada uno en proporción de sus necesidades? Noveno, ¿cuál será y cómo se forjará el criterio comunitario para generar y, en su caso, reproducir, los bienes que se distribuirán: por necesidad natural o cultural? Finalmente, alcanzada la igualdad, ¿cómo se hará para mantenerla y desarrollarla dentro de la comunidad? ${ }^{46}$ ¿La igualdad será para siempre?

La sinapsis de la memoria para formular respuestas es completamente distinta a la cronología para plantearlas; la comunicación entre ambas consume días, años, y muchas veces quedamos inmersos en dificultades insuperables. Las preguntas aquí deslizadas han tomado más tiempo del esperado. Sin enamoramiento, las posibles respuestas pertenecen a un estadio arcádico. Porque idílico es el campo para representar, magnamente, la relación de los individuos con los estados de cosas materiales que existen en el mundo. Además, si fuese ostensible la eficacia iluminante de las doctrinas igualitaristas para establecer la igualdad sustancial, no se hallarían tantos comunismos ni tantos socialismos.

La doctrina igualitaria más ortodoxa implicaría la igualdad entre todos los individuos en todos los bienes. Queda descartada por ser imposible, desde el punto de vista empírico. De modo razonable, corresponde preguntarse qué aspectos del igualitarismo, acaso relativo y parcial, serían susceptibles de ser instaurados en una sociedad abierta. Si se tratase de averiguar quiénes plantaron, originariamente, uno de sus incentivos más atractivos ${ }^{47}$, quizá se deba acudir a los constituyentes que labraron la Costituzione della Repubblica Italiana de 1947.

Principios fundamentales

(...) Art. 3

Todos los ciudadanos tienen la misma dignidad social y son iguales ante la ley sin que pueda prevalecer distinción alguna por razones de sexo, raza, lengua, religión, opiniones políticas u otras circunstancias personales y sociales.

${ }^{46}$ Boвbio, Norberto, Igualdad y libertad, op. cit., pp. 79-83.

${ }^{47}$ En el artículo 11 de la Constitución de la Ciudad de Buenos Aires de 1996, se puede leer una regla semejante. 
Corresponde a la República remover los obstáculos de orden económico y social que, limitando el derecho a la libertad y la igualdad de los ciudadanos, impiden el pleno desarrollo de la persona humana y la participación efectiva de todos los trabajadores en la organización política, económica y social del país.

El principio de igualdad sustancial es un paradigma de la Constitución italiana, una norma distinguida dentro del propio orden jurídico, porque emplaza y sitúa a la «República» a «remover los obstáculos de orden social y económico» que limiten la igualdad de los ciudadanos e impidan el pleno desarrollo de su inherente personalidad. Así, calificadísima doctrina la ha juzgado como el más robusto de los significados políticos de entre todos los que la Constitución ofrece a los italianos, ya que hace de «la justicia social condición indisoluble de la libertad política y de la igualdad jurídica» ${ }^{48}$. Las determinaciones concretas de la igualdad sustancial, estipuladas en el artículo 3 de la Constitución italiana, sugieren que ella no encierra una versión ortodoxa del igualitarismo, dado que la Constitución de Italia también se compagina con la libre «iniciativa privada» en el ámbito de la economía (art. 41); empero, tampoco se limita a sugerir una mera paridad de los ciudadanos en cuanto a su capacidad económica.

Constitucionalmente, sin dudas, los poderes públicos de la República deben realizar intervenciones positivas encaminadas a corregir desigualdades de hecho que han tenido origen en injusticias del pasado. Las intervenciones que la Constitución pone a cargo de la República no se enfilan a realizar una sistemática y general distribución de la riqueza y de las rentas. Se aspira, eso sí, a que las prestaciones aseguren, de manera positiva, a los ciudadanos desfavorecidos. En este sentido, la Constitución italiana ofrece una «solución intermedia» entre el igualitarismo ortodoxo o más radical («a cada individuo según sus necesidades») y la mera igualdad de Derecho ( «a cada individuo según sus méritos o capacidades»). No se configura una nivelación general, pero sí se estipulan límites mínimos y máximos que aseguren a todos una vida decorosa y segura ${ }^{49}$.

En resumen, la República de Italia, según la dicción constituyente, basa el acuerdo fundacional en la realización «del máximo posible de justicia social» ${ }^{50}$. Esta igualdad sustancial también se articula con otras reglas constitucionales ordenadas en el mismo Código ${ }^{51}$. No es la arquitectura jurídica de ningún paraí-

48 Calamandrei, Piero, La constitución inactuada, Madrid, Tecnos, 2013, p. 144.

49 Pizzorusso, Alessandro, Lecciones de Derecho constitucional, t. I, Madrid, Centro de Estudios Constitucionales, 1984 , pp. 163-173.

50 Ibid., p. 172.

51 Cabe mencionar, sin exhaustividad, los contenidos dispuestos en los siguientes artículos de la Constitución de la República Italiana: 4 (derecho al trabajo); 6 (minorías lingüísticas); 24.3 
so en el planeta Tierra, ni sus reglas constitucionales son inmaculadas. Sin embargo, su riqueza es patente y su artículo 3 prescribe, claramente, un camino para que todos los hombres alcancen el máximo posible de satisfacción de sus expectativas y aspiraciones económicas y materiales; amén, desde luego, de las morales.

Hago un esfuerzo por congraciarme con la CF, pero no encuentro en ella ningún igualitarismo. No existe un principio de igualdad sustancial; al respecto, en sus páginas no hay razones; el silencio que preside es sobrecogedor. Me pregunto entonces: ¿la falta de cultivo de un «jardín» sobre reglas constitucionales referidas a la igualdad sustancial es una de las causas de la pobreza y de la vulnerabilidad que padecen el 60\% de los habitantes de la Argentina? ¿Una CF despoblada de reglas que ordenen al Estado actuar, de un modo consistente, sobre la igualdad de hecho hunde a sus habitantes en la insatisfacción de sus necesidades básicas? La CF dormita; sus reglas sobre igualdad de oportunidades, hacinadas, no redimen el ahogo inducido por la ausencia de normas sobre una intervención estatal que, con moderación, ordenase una nivelación racional en la distribución de la riqueza.

\section{PROSPECTUS 52}

Las escrituras del Derecho constitucional, severamente codificadas, disponen cómo ha de gobernarse una comunidad. Instaurar en una constitución, con un solo trazo, la idealidad sobre determinados fines comunitarios constituye un acto de gobierno constituyente. Quiero decir, sin alardes, que un estado de cosas se comprende en la escritura de la constitución y otro estado de cosas se revela en el acto de gobernar cotidiano de las autoridades constituidas.

La autoridad del Derecho debiera comprender un solo estado de cosas: el constitucional, que surge del poder constituyente. No obstante, la realidad demuestra, con sostén suficiente, un cóctel perturbador. Así, por un lado, se exhibe una escritura verosímil pero en ocasiones dueña de un significativo grado de ineficacia: la constitucional, generada por la autoridad constituyente. Por otro

(asistencia judicial); 31 (protección de la familia, maternidad, infancia y juventud); 32 (derecho a la salud); 37 (trabajo de mujeres); 34 (derecho a la educación); 42 (función social de la propiedad) y 53 (progresividad tributaria).

52 En 1793, Jean-Antoine-Nicolas de Caritat (Condorcet), junto a Emmanuel Sieyès y Jules Duhamel, publicaron el Journal d'instruction sociale par les citoyens. Condorcet tituló de este modo (Prospectus) a las palabras introductorias (Paris, Edhis, 1981, disponible en http://gallica.bnf.fr/ ark:/12148/bpt6k97249, consultado el 7/9/2016. 
lado, la realidad muestra un dramático discurso inverosímil, impostor e impostado, pero muchas veces eficaz: el gobierno propio del Estado, generado por las autoridades constituidas. En otras palabras, la escritura constituyente sobre el gobierno del Estado, por un lado, y, por el otro, el discurso concreto sobre el gobierno constitucional, cotidiano y corriente, del Estado. Una pendiente, a veces lamentablemente secreta, de las escrituras políticas que constituyen al Estado constitucional.

La escritura constitucional es lengua y coerción. Sin palabras escritas, no hay discurso dominante. Sin normatividad, la constitución no impone ni la unidad del orden jurídico ni su gradación o escalonamiento, y su escritura queda en aplazamiento, transitorio o eterno. Ahora bien, ninguna escritura constitucional, por sí sola, determina la expansión o contracción de los hechos políticos, sociales, culturales y económicos, ni establece la igualdad fundamental entre sus habitantes. En sintonía con lo adelantado en la sección I, aquí postulo dos nuevas normas que provocarían la expansión del orden jurídico constitucional del Estado. Naturalmente, la prosa anunciada no solucionará por sí misma — ni lo pretende- el drama de la masa de desposeídos. La pretensión se enlaza, apenas, con una nueva significación de la que podrían recogerse frutos maduros. Porque la constitución objetivada es fundamentalmente una norma sobre procesos públicos, pero también expresión de un «estadio de desarrollo cultural» del pueblo ${ }^{53}$, que conjuga en su interior normas de adaptación a cambios ya producidos y normas de aliento o promoción que tratan de producirlos. También la teoría de la constitución posee semejante vocación cultural, dado que puede desarrollar los «fundamentos de las esperanzas» ${ }^{54}$ de un pueblo.

El principio constitucional de igualdad es la «premisa básica del Estado ${ }^{55}$, fundamento indiscutido que proporciona el orden constitucional. Por lo tanto, la tarea teórica normativa que aquí expongo no deberá comprenderse en el sentido de que con un par de reglas se viabilice sencillamente la igualdad fundamental. Tales prescripciones no tienen ningún embrujo; sólo comprenden la historia de la Argentina y la recuerdan. Para que la igualdad se pueda concretar con algún grado de sustantividad, harían falta varias reglas; no bastaría con una díada.

Con el nacimiento del par de reglas que abajo anuncio también se deberían instaurar otras directivas, por ejemplo, sobre la cuestión tributaria y respecto del dominio de los recursos naturales. Sin embargo, más allá de que

53 HäBerle, Peter, El estado constitucional, México, IIJ, UNAM, 2001, p. 5.
54 Ibid.
55 Zaffaroni, E. Raúl et al., Derecho penal, Buenos Aires, Ediar, 2000, p. 22. 
antes de concluir esta misma sección hago afirmaciones concisas sobre estas cuestiones y a continuación retomaré algún aspecto conceptual, no soy dueño de todas las palabras. Después de andar, imaginé esta composición basada en dos reglas, reservadas, por cierto, exclusivamente a la configuración constituyente, función jurídica eminentísima que sólo se puede desarrollar de acuerdo al proceso instaurado en el artículo 30 de la CF, según el cual individuos igualmente libres reforman el «orden entre los asociados» ${ }^{56} \mathrm{de}$ una comunidad determinada por la mediación de sus representantes auténticamente elegidos en comicios libres.

La doble postulación juega un rol doble: primero, una ruptura con el pasado; segundo, una utopía. Ambas reglas cotizan por igual y no describen la realidad constitucional, pretenden influir en ella. Porque el principio y la continuidad de la desigualdad sustancial en la Argentina siempre ha obedecido a la siguiente marcha fúnebre: el endeudamiento constante del Estado y, en paralelo, la ausencia de un compromiso seminal con la justicia social.

Asumo, de modo consistente, la ruta del saber normativo o teoría prescriptiva. Pienso que los argumentos son suficientes y singulares para promover la igualdad fundamental, sustancial, con base teórica y sin radicalismos. Dado que no es factible hallar dentro de las instituciones jurídicas un orden totalmente perfecto, siempre se ha de analizar cuál es el modelo que muestra mayores fortalezas y cuál el que exhibe menores inconvenientes. Es evidente que la igualdad sustancial, sin ortodoxia, resulta mudable y muchas veces inasible según el modelo de la CF. Mientras, la injusticia social crece con energía. Albert Camus sostuvo que el papel de escritor es inseparable de difíciles deberes: por definición, no puede ponerse hoy al servicio de quienes hacen la historia, sino al servicio de quienes la sufren ${ }^{57}$.

Pido la comprensión del lector: no es posible redactar reglas sobre igualdad fundamental y deuda externa, como hago más abajo, y pretender su ubicación en la cabecera y en el cierre de un futurible texto constitucional de ciudadanos elegidos por el pueblo, sin referirme a otras materias (soberanía popular, laicidad, libertad, dignidad, pluralismo, buena fe, relaciones internacionales, etc.). Por ende, estas cuestiones son objeto de individualización aunque no de tratamiento. Asumo el riesgo.

56 V. Calamandrei, Piero, Sin legalidad no hay libertad, Madrid, Trotta, 2016, p. 34.

57 Camus, Albert, «Discours de Suède», París, Euvres, Gallimard, 2013, p. 80 [10. XII.1957]. 


\section{A. Regla de apertura}

La soberanía reside en el pueblo, fuente de toda la autoridad del Estado. Todos sus habitantes son iguales en libertad y ante el Derecho.

La Argentina es un Estado democrático, laico y federal, basado en la protección de la dignidad humana y su misión primordial es realizar la igualdad fundamental entre todas las personas.

La República instituida por esta Constitución como forma de gobierno se orienta por el pluralismo, la participación, la publicidad y la racionalidad.

La soberanía del pueblo se integra con porciones, trozos o fragmentos del poder de cada ciudadano; en su cuna, la igualdad en la libertad que debe conferirse a cada ciudadano para constituir y administrar la comunidad; más precisamente, con la que «deben participar de los beneficios y cargas de la sociedad» ${ }^{58}$, lo cual constituye un presupuesto de esa misma configuración soberana. Por eso, la igualdad ciudadana se instala como directiva objetiva de fundamentación del ente estatal e implica el propio proceso de construcción de una comunidad política (V. sección II).

El Estado constitucional debe ser el «garante de la igualdad jurídica inherente al respeto a la dignidad de la persona» ${ }^{59}$, pero en la realidad no existen ni existieron entes estatales perfectos que puedan ser catalogados como modelos ideales. La lucha por la igualdad se despliega de modo constante dentro del envase jurídico que contiene al Estado constitucional.

Los niveles de desigualdad y exclusión entre los habitantes de la Argentina, denunciados en la sección I, comprometen sus dignas y propias condiciones materiales de existencia y desarrollo. Por definición, los excluidos son casi un $60 \%$ de la población y los incluidos, un $40 \%$; naturalmente, son desiguales entre ellos. Esta desigualdad se origina en la distribución de la riqueza y en las diferentes opciones respecto de la satisfacción lograda o que espera lograrse sobre los bienes económicos. Sin formular nociones universalistas, ¿se sostiene una comunidad desordenada bajo la lesa desigualdad? ¿Se puede argüir que estos indicadores no sirven para nada? Debería pensarse que el régimen de ordenación para los individuos satisfechos, que los iguala de hecho y de modo suficiente en cuanto al disfrute de las condiciones materiales expectantes, también debería abarcar a los individuos insatisfechos. Francamente, desde el punto de vista teó-

58 GonZÁlez, Florentino, Lecciones de Derecho constitucional, París, Ch. Bouret, 1889, p. 54.

59 Zaffaroni, E. Raúl, «Derecho, derecho penal humano y poder financiero» (Conferencias de Guatemala), inédito, gentilmente cedido por su autor, agosto de 2016, p. 49. 
rico tiene mucho sentido, pero el conflicto se presenta en la práctica: ¿cómo incluir a los excluidos que penan con su penosa desigualdad que favorece su insatisfacción sobre los bienes objeto de reparto?

El grado de desigualdad resulta alarmante. En efecto, la cuestión sobre la justicia social se relaciona con la edificación de la democracia. Tantas personas excluidas, sin dudas, debilitan el elemento natural del Estado; sobre este punto, sería razonable sospechar que el propio Estado no supiese o no pudiese «mantener el control de sus efectos en la vida de las poblaciones» ${ }^{60}$; dado que el Derecho, que reglamenta el monopolio de su fuerza, podría ser impracticable. Si los pobres y vulnerables resultasen finalmente excluidos de un disfrute mínimo de las condiciones materiales de existencia, ¿por qué tendría sentido que siguiesen participando de una democracia en la que, por lo menos, no son atendidos?

La descripción de la estructura de nuestra sociedad da lugar a dos subjetividades: por un lado, la de los incluidos que han de tener «una gran satisfacción de sí mismos» ${ }^{61}$, y se aprecian mucho; y, por otro, la de los excluidos, que cuentan con su fuerza de trabajo y son usuarios y consumidores, pero su subjetividad se encuentra desalineada. En paralelo, no se podría negar el indeseable hecho de que los excluidos comprendan, al fin, que la ordenación comunitaria sólo cobija - con ventajas injustas e inalcanzables - a un «conjunto de ciudadanos adinerados que ejercen su influencia en el gobierno del Estado» ${ }^{62}$. Por ejemplo: ¿por qué un excluido del reparto comunitario, cuyos padres no tienen trabajo y él tampoco, ponderaría los beneficios de la ordenación constitucional, que poco o nada hace por él? ¿Por qué no ha de pensar que, en rigor, se trata de una plutocracia, al menos respecto de él y su familia? La desigualdad es significativa y traumatizante y, como muy bien se ha dicho, la "presión de los excluidos», en determinado momento, se «vuelve irresistible» 63 .

El principio constitucional de igualdad no eliminará la desigualdad. Sin embargo, el Estado tiene una «misión primordial»: su fuente de justificación, precisamente, consiste en reducir las divergencias existentes sobre las condiciones materiales. Además, tal igualdad es calificada como «fundamental» para que no queden dudas respecto de la tarea sobre la legitimidad de su actuación.

La misión del Estado, en tanto poder o facultad que el pueblo le otorga, debe ser luchar contra la riqueza extrema y contra la pobreza semejante. Con las definiciones constitucionales actuales no se puede luchar contra la desigualdad; por

60 Badiou, Alain, Nuestro mal viene de más lejos, Buenos Aires, Capital Intelectual, 2016, p. 60.

61 Ibid., p. 45.

62 Véase definición de «plutocracia» en el DRAE.

63 V. Ferrajoli, Luigi, «La igualdad y sus garantías», Anuario de la Facultad de Derecho de la Universidad Autónoma de Madrid, n. ${ }^{\circ} 13,2010$, p. 324. 
lo menos para ponerle remedio suficiente. Una nueva política sobre justicia social en la comunidad requiere, inevitablemente, la configuración de «consensos básicos» ${ }^{64}$ sobre esa matriz, cuya discusión significativa puede generar, quizá, una nueva identidad plural. Se hace necesario que cada ciudadano se pueda colocar en el sitio del otro, en especial, el sitio de los desposeídos. Propongo un viaje solidario, porque el único modo de igualar a los desaventajados supone — exige - un acuerdo político basado en la fraternidad.

No se solicita que los hombres sean iguales en todo; la función del Estado consiste en que los sistemas operen para satisfacer las necesidades básicas individuales e impedir la concentración de riqueza, que corroe la democracia al generar desigualdades notables. La acumulación desmedida de riqueza, además, suele impactar en la estructura del poder del Estado; por consiguiente, su identidad transmuta con rapidez y mina el territorio de la juridicidad, la vuelve inexplicable, y de allí, sin solución de continuidad, deviene al abuso de su posición dominante y hegemónica.

Toda comunidad requiere reglas para su ordenación; en el modelo propuesto, la gobernanza del Estado debe intentar, remediar o acotar, mediante una disciplina racional y participativa, la injusticia social. Pero hay más. Remediar la desigualdad es un pensamiento estratégico; una vez constitucionalizado, la justicia social como misión fundamental de la gobernanza estatal se consolida como un bien indisponible. Significa que corresponderá distinguir entre «alternancia» en la gobernanza y «eliminación» de sus condiciones elementales.

\section{B. Regla de clausura}

La República Argentina cancela su deuda de buena fe, bajo condición de trato transparente, equitativo e imparcial. No cancela deuda que signifique la frustración del derecho al desarrollo de sus ciudadanos o al inherente a sus generaciones futuras. Tampoco paga deuda originada en actos contrarios al orden democrático instituido por esta Constitución, ni la que haya sido originada por una rebelión o en desprecio de su juridicidad. La inmunidad soberana de jurisdicción y ejecución en la reestructuración y pago de la deuda no se debe disponer. Se prohíbe la cesión de jurisdicción soberana o transferencia de competencias a instancias de arbitraje internacional o a tribunales semejantes con aplicación de legislación extranjera, en controversias originadas por la asunción de deuda, ya sea por actos de imperio o de gestión estatal.

${ }^{64}$ HäBERLE, Peter, El estado constitucional, op. cit., p. 119. 
La Argentina fue una colonia hasta la declaración de su independencia, en julio de 1816, de los Reyes de España, sus «sucesores y metrópoli» y de «toda otra dominación extranjera». Recordamos el bicentenario. Casi toda la historia del Estado ha estado signada, atropellada, obstaculizada o limitada por el endeudamiento externo, salvo una bonanza durante la regularidad constitucional entre el 4/6/1946 y el 21/9/1955. En diciembre de 2001 se declaró la bancarrota, la quiebra de la Argentina. Durante casi quince años — muchas veces con prisa, otras con algún descuido, otras con dolo o mera culpa-, la autoridad pública dispuso emprender el camino de la renegociación para el pago de las obligaciones.

Todo Estado soberano debe disponer de una constitución si desea ser parte y reconocido por las Naciones Unidas. Todo Estado soberano, para desarrollar sus negocios internacionales, debe honrar el pago de sus deudas ${ }^{65}$. El arreglo de la deuda pública del Estado argentino constituye una atribución del Congreso, conforme la regla del artículo 75, inc. 7 , de la $\mathrm{CF}^{66}$. La implementación de los acuerdos corresponde al Poder Ejecutivo.

Las obligaciones de pago, en materia de capital e intereses de la deuda externa, costas y costos, comprometen muchos años y generaciones. El termómetro de la opresión actual marca más de 160.000 millones de dólares ${ }^{67}$. La colosal deuda externa hiere las posibilidades de desarrollo de quienes habitan actualmente la Argentina y también las de los «argentinos por nacer», porque los compromisos de pago han sido asumidos por varias «décadas». El porvenir, acaso, no es totalmente nuestro. La lección es, entonces, que todos los servidores públicos que administraron con irresponsabilidad han condenado el presente y se convierten también en verdugos del futuro; en especial, de quienes no han nacido. El fabuloso endeudamiento externo, en estos términos brutales, significa una nueva forma de esclavitud o sojuzgamiento, porque existe una tensión perpetua entre posibilidad concreta de desarrollo y cumplimiento de obligaciones internacionales. Además, coloca a la CF en una zona inhóspita; intimidadas, sus reglas, se desvanecen. Se produce así que los hombres desdichados del pre-

65 Art. 4, CF: «El Gobierno federal provee a los gastos de la Nación con los fondos del Tesoro nacional formado del producto de derechos de importación y exportación, del de la venta o locación de tierras de propiedad nacional, de la renta de Correos, de las demás contribuciones que equitativa y proporcionalmente a la población imponga el Congreso General, y de los empréstitos y operaciones de crédito que decrete el mismo Congreso para urgencias de la Nación, o para empresas de utilidad nacional».

66 Art. 75, CF: «Corresponde al Congreso: (...) 7. Arreglar el pago de la deuda interior y exterior de la Nación».

67 Instituto Nacional de Estadísticas y Censos, Serie Histórica, Deuda externa disponible en http://www.indec.mecon.ar/nivel4_default.asp?id_tema_1=3\&id_tema_2=35\&id_ tema_3=45, consultado el 7/9/2016. 
sente, encerrados a pagar una deuda que no los beneficia, transmiten semejante desdicha y encierro, con pujanza, a las generaciones venideras. Difícilmente una criatura viva pueda imaginar un catecismo semejante en contra del humanismo. Mientras tanto, la muchedumbre ciudadana deambula en el aislamiento de cualquier hipótesis mínimamente verificable sobre justicia social, victimizada por un presente con testimonios de disolución.

La mayor garantía de que se dispone para emprender el camino de la justicia social reside en los recursos del Estado. A menores recursos, porque hay que cancelar una deuda externa cada vez más cruenta, menor o nulo desarrollo de la justicia social. Prédica sencilla y sincera. ¿Puede causar extrañeza la relación existente entre la producción de bienes y servicios y la deuda externa? El pago de los servicios del endeudamiento constituye una pena, cuya naturaleza endiablada afecta cualquier alternativa igualitaria sobre la distribución de la riqueza.

En consecuencia, la sumisión jurisdiccional que provoca el endeudamiento externo deberá discutirse en sede constituyente. Sin dudas, deberá considerarse la eventual prohibición de determinación o prórroga a la «jurisdicción internacional», con semejante énfasis al empleado en el artículo 29 de la CF, por el que se prohíbe al Congreso la concesión al Poder Ejecutivo de «facultades extraordinarias», o la «suma del poder público», u otorgarle «sumisiones o supremacías por las que la vida, el honor o las fortunas de los argentinos queden a merced de gobiernos o persona alguna»; actos que «llevan consigo una nulidad insanable, y sujetarán a los que los formulen, consientan o firmen, a la responsabilidad y pena de los infames traidores a la patria». Conforme al artículo 116 de la $\mathrm{CF}^{68}$, no parece razonable el hecho de que el Estado argentino sea «juzgado» en Nueva York por un «asunto» que el propio artículo 75, inc. 7, atribuye al Congreso federal y lo coloca específicamente sobre el órgano: «arreglar el pago de la deuda interior y exterior de la Nación». No puede pedirse a un juez de Nueva York que se preocupe por el aliento, fomento o estímulo real de la justicia social de los argentinos excluidos del orden económico.

Si todo esto se reconociera con facilidad, el debate sería más ameno y provechoso. El endeudamiento externo es un refinado instrumento de dominación en manos de «organismos internaciones controlados por los países colonizadores» ${ }^{69}$, los cuales quieren hacernos creer que la justicia social es un lujo. Pues no lo es; sencillamente, en el contexto de las repúblicas latinoamericanas, «gobernar es igualar».

68 Art. 116, CF: «Corresponde a la Corte Suprema de Justicia de la Nación y a los tribunales inferiores de la Nación, el conocimiento y decisión de todas las causas que versen sobre puntos regidos por la Constitución, y por las leyes de la Nación, con la reserva hecha en el inc. 12 del artículo 75; y por los tratados con las naciones extranjeras...».

69 V. Zaffaroni, E. Raúl, El Derecho en la fase superior del colonialismo, op. cit., p. 43. 


\section{Entreacto. Tributación y dominio de los recursos naturales}

Primero. Todo Estado debe disponer de recursos para afrontar sus gastos. Por ello, la «contribución pecuniaria» para solventar los gastos de la comunidad organizada se presenta como un insumo natural y comporta, a la vez, una «restricción al derecho del hombre sobre sus bienes y sobre los frutos de su trabajo» ${ }^{70}$.

De acuerdo con el Presupuesto General de la Administración para el Ejercicio 2016, la mayoría absoluta de los ingresos del Estado argentino provienen de fuente tributaria. En la Argentina, el artículo 17 de la CF consagra el principio de juridicidad tributaria: «Sólo el Congreso impone las contribuciones que se expresan en el artículo 4». En el reparto federal, las competencias de este órgano sobre la materia tributaria son disciplinadas, constitucionalmente, en el artículo 75 .

Además, en la Argentina, la masa tributaria, que ingresa para solventar los gastos del Estado federal, se conforma, casi en sus tres cuartas partes, por impuestos indirectos, francamente regresivos, que desatienden la capacidad contributiva y no contemplan la equidad social. La política constitucional que fomente la justicia social debería ser exactamente al revés: el orden tributario debería fundarse, de modo sustantivo, en el criterio de progresividad sostenido en la capacidad contributiva; ergo, impuestos directos. Dado que la progresividad tributaria constituye un criterio equitativo para la imposición, la constitución debería inspirarse en la progresividad como criterio de reparto para el ejercicio de su potestad tributaria.

A los fines de una política constitucional orientada a la justicia social, la prescripción del actual artículo 16 de la CF es una regla honrada y necesaria ( «La igualdad es la base del impuesto»), aunque insuficiente. Para que se produzca una reducción de la desigualdad es menester también escribir y decidir los hechos imponibles que merecerán trato semejante o que se serán objeto de referencia para un trato igual. Sin esa determinación previa, por ejemplo, persistirá, en los ingresos tributarios del Estado, la notoria injusticia determinada por el hecho de que el consumo de los pobres y vulnerables, insustituible para su propia existencia, alivie la presión tributaria sobre las rentas de los ricos.

Segundo. En cualquier alegoría sobre la injusticia social, resulta indispensable llamar la atención sobre la tierra y sus recursos naturales, elemento crucial que hace a la configuración de un Estado. Porque son bienes públicos indivisibles, la igualdad debe ser asegurada por la gobernanza pública. En la CF, reformada

70 GonZÁlez, Joaquín V., Manual de la Constitución Argentina, Buenos Aires, Estrada, circa 1920 , p. 111. 
en 1994, se dispuso un inequitativo compromiso federal, en el artículo 124 de la CF: «Corresponde a las provincias el dominio originario de los recursos naturales existentes en su territorio». Se trata de una incorrecta decisión constituyente que no promociona la justicia social. Produce un nuevo tajo, hiriente y doloroso, a la igualdad, dado que discrimina sin razón ni escrutinio: ciudadanos de provincias que tienen riqueza natural y ciudadanos de provincias que no tienen tanta riqueza natural. Aquí, la ciudadanía se vuelve un privilegio, circunstancia que produce consternación, ya que ella fue inventada, con honradez, para igualar. Considero que el dominio de la naturaleza debe ser originariamente del Estado, no de las provincias. Eso evitaría equívocos y aumentaría la fraternidad federal.

Si algún día el saber constitucional adquiriese el estatus total de ciencia formal y escapase a las fatalidades de la ideología o a la naturaleza precaria e inestable del universo sensible, correspondería entonces recordar el inmarcesible paradigma del artículo 27 de la CPEUM. La lengua dichosa de su imaginario, que incita por su originalidad y pureza, con sus propósitos igualitarios, nos vuelve devotos de su siembra constituyente. En la lengua politizada de la Constitución mexicana de 1917 no hay retórica vacía. Trae a la luz del día el significado de la justicia social. El espacio del artículo 27 de la CPEUM abarca casi el $10 \%$ de la textura finita de las aproximadamente 22.000 palabras, escritas en la ciudad de Querétaro, en 1917. Ciertamente, no es la única regla sobre igualdad social, aunque es sin dudas un emblema.

Su modelo, absolutamente radical, se comprometió y encontró el mayor grado de justeza semántica porque nada del pasado del constitucionalismo le era semejante o asimilable. Atraviesa todo lo realmente apreciable del mundo natural y ofrece la idea de que su lengua constituyente lo contemplaría: dominio estatal originario de las tierras y aguas comprendidos dentro de los límites territoriales, interés público y propiedad privada, distribución equitativa de la riqueza pública y su cuidada conservación, fraccionamiento de los latifundios; dominio estatal directo de todos los minerales, capacidad para adquirir el dominio de las tierras y aguas de la Nación, fijación de la extensión de tierra de la que puede ser dueño un solo individuo o sociedad. Criterios sobre la igualdad social como los recién expresados significan un faro iluminador de nuestro Derecho constitucional en América Latina.

\section{COMENTARIOS FINALES}

Primero. La escritura constitucional expresa una comprensión del mundo e intenta imponer, con su propia lengua, la posición que se adopta para su ordenación. 
Segundo. En la obra escrita, el principio de igualdad, con sus complejos significados y profundas implicancias, se constituye como una norma que da propio fundamento, al instituirse como línea de acción, al propio Estado.

Tercero. La igualdad ante el Derecho, enunciado lingüístico y convencional, se convierte en un orden fundamental en la historia de una comunidad política. A partir de su positividad, de su concreta vanguardia en el texto constitucional, el pasado que se haya regido en su ausencia siempre será capturado como desgarrador y, a menudo, censurado sin absolución por su afrenta a la dignidad humana ${ }^{71}$.

Cuarto. Si todos somos igualados ante el Derecho, si el tratamiento que se debe ofrecer desde el orden jurídico resulta semejante para todos los habitantes, no debe existir ninguna duda: el ejercicio del poder público debe basarse, exclusivamente, en el Derecho positivo. Por ende, la igualdad ante el Derecho constituye un baluarte de la constitucionalidad.

Quinto. Los criterios sobre la igualdad de oportunidades, independientemente de la obediencia o desobediencia a sus prescripciones, es decir, de la discrepancia inherente entre normatividad y efectividad, son escrituras en las que su constituyente, las palabras, se encuentran sometidas a determinado orden y semejante significado. Sin embargo, al final del «recorrido», la igualdad de oportunidades no iguala en los fundamentos. Su cometido es igualar la partida, no cómo se hace para llegar al propio punto de partida.

Sexto. En plena luz del día, la justicia social es una bendición laica. Por su acción se puede procurar reducir la mortificación, daño que produce la exclusión social como la pobreza o situación vulnerable semejante.

El endeudamiento externo del Estado argentino, es una dolorosa situación que cercena una salida con justicia social. Se ha pagado durante casi dos siglos, y la deuda crece. En estas situaciones, la justicia social es una aventura, que también posee noble y robusta legitimación. Por eso, poner coto a la desigualdad creciente está supeditado al futuro de la deuda.

Intentar que la justicia social sea la misión fundamental del Estado significa transformar la realidad. Oponerse al estado de cosas real incluye una nueva orientación y una nueva «vocación del pensamiento» ${ }^{72}$, plena de realismo y naturaleza auténtica, que se desarrolle en renovado auditorio ciudadano, cuya ligazón con el pasado sea el respeto estricto al proceso de variación de la CF. Tal actividad puede ser alimentada con normas de la más alta jerarquía, en la inteligencia de

71 Torres del Moral, Antonio: ¿Qué igualdad?», en Revista de Derecho Político, núm. 44, 1998, p. 80.

72 Badiou, Alain, Nuestro mal viene de más lejos, op. cit., p. 19. 
que la norma constitucional gobierna un proceso público sobre el bienestar de los individuos en la comunidad.

Séptimo. Mis ideas son expuestas sobre fragmentos relevantes del principio de igualdad, según el orden instituido por la CF, tal como anuncié en la sección I. No descarto que generen otras inferencias, las que - en otro momento y en otro lugar — sean susceptibles de tipificar aspectos básicos sobre la «identidad» del constitucionalismo en América Latina.

Octavo. Mis palabras tienen una vocación: desemejanza total con su caída libre en caldero roto, porque los vacíos o lagunas del Derecho constitucional, que contemplan o desarrollan «una desigualdad sin precedentes en la historia», colocan a nuestras democracias en sitios de inestabilidad y fragilidad muy difíciles de sostener durante mucho tiempo más ${ }^{73}$.

Noveno. Propiciar un modelo que sostenga una mayor intervención del Estado en el reparto y disfrute de los bienes yacentes y que sean creados con la misión de la justicia social, no significa un ideal perfeccionista. El Estado debe asegurar que cada individuo pueda, libremente, desarrollar su plan de vida escogido sin interferencias de ninguna clase, porque así se legitima el Estado en su juridicidad más estricta. La desigualdad social creciente se constituye en un escollo que impide el propio plan que se eligiese, dado que puede llegar a comprometer la paz relativa.

Dentro de las herramientas disponibles en la comunidad argentina, el Estado promotor resulta el más razonable, además de su papel histórico como gestor. ¿O acaso se librará a la iniciativa privada o a la mano invisible del mercado la concreción de la justicia social? Las cosas que están en el mundo son naturales y culturales; las primeras establecen sus propios procesos para su control, desarrollo y finitud; las segundas —en particular, la economía y el Derecho- deben ser procesadas y desarrolladas, siempre, por el hombre. Se trata de artefactos creados para ordenar la convivencia. Puesto a elegir y sin creer en la existencia de valores objetivos, la experiencia señala, sin perdón, qué sucede y qué sucederá con los excluidos — por vía de hipótesis muy segura - si la economía solamente la manejan los poderosos. Mientras que los representantes o servidores públicos en algún momento culminan su ejercicio de los poderes constitucionales y republicanos, los poderosos siempre intentarán ejercer su dominación, en todo tiempo y espacio.

La justicia social es una idea regulativa cambiante. Cada comunidad de individuos debe buscar, desarrollar y mantener la suya, con asiento indisponible en la libertad de cada uno de ellos para decidir y determinar su presente y su futu-

73 V. Ferrajoli, Luigi, «La igualdad y sus garantías», op. cit., pp. 321-322. 
ro. Esta igualdad en libertad se asienta, a su vez, en la individual dignidad de cada ser humano.

Décimo. La infeliz laguna del Derecho constitucional sobre igualdad fundamental y la semejante inefectividad constitucional de las reglas sobre igualdad de oportunidades también afecta al principio de igualdad, porque la divergencia o la ausencia de normas observan su asiento en la inevitable existencia entre ser y deber ser del Derecho constitucional. El vacío debe ser completado con nuevas reglas de Derecho constitucional, construidas en el ágora ciudadana, gracias al proceso de creación normativa fijado en el artículo 30 de la CF. Mientras esto no ocurra, un derecho de producción contractual y privada, con reglas de insostenible adhesión, intentará sustituir o colmar la laguna de la $\mathrm{CF}$, y hará valer, en general, «la ley del más fuerte» ${ }^{74}$.

Igualar fundamentalmente a nuestra ciudadanía constituiría una misión inigualable para su propio bienestar general y el de las generaciones futuras, anunciadas y protegidas desde el Preámbulo de la Constitución federal de la Argentina.

Title:

To rule is to equalize. Isonomy, opportunities and social justice in Argentina.

\section{Summary:}

I. Prelude. II. State, Constitution and equality. III. Criteria on equality. IV. Prospectus. V. Final comments.

\section{Resumen:}

El Estado constitucional es la máxima instancia conocida para la ordenación política de una comunidad de individuos libres. Las dimensiones de la igualdad, con diverso significado y grado de reconocimiento, pretenden cobijar una determinada fundamentación del Estado, al equiparar por convención aspectos de las relaciones entre los hombres. La igualdad ante el Derecho significa una de sus fortificaciones. Un nuevo logro reside en la igualdad de oportunidades. Ambas son insuficientes porque no detienen la marcha regresiva del bienestar. La

\footnotetext{
${ }^{74}$ Ibid., p. 321.
} 
desigualdad creciente en la Argentina, donde casi el $60 \%$ de su población es pobre o vulnerable, exhibe la existencia de dos mundos: una ciudadanía política y una ciudadanía social. Los desposeídos, pobres y vulnerables, no disfrutan y no pueden disfrutar, con el actual estado de cosas constitucional, de una ciudadanía de plena justicia social. Nunca será posible destruir por completo la desigualdad social, sino sólo disminuirla. Un progreso con justicia social se presenta como misión fundamental del Estado. La reducción del dualismo en los grados de la ciudadanía es propiciada con múltiples energías. Una puede provenir de un consenso básico, regido por la Constitución federal en su proceso de variación. Mientras no se produzca un reparto más igual de los bienes, la lengua de las escrituras laicas será mejor comprendida por aquellos que conozcan los beneficios de una ciudadanía completa y conozcan todas sus luces.

\section{Abstract:}

The constitutional State is the highest instance known for the political organization of the community of free individuals. The dimensions of equality, with different signification and degree of recognition aim to cover a certain grounding on the State, when they equate by convention aspects of the relationships between human beings. The equality before the law means one of its strengthenings. One new achievement: equality of opportunity. Both are insufficient because they do not prevent the regressive march of well-being. The growing inequality in Argentina, were almost 60\% of its population is poor or vulnerable, shows the existence of two worlds: a political citizenship and a social citizenship. The deprived, poor and vulnerable people do not enjoy -nor could they- the current state of constitutional affairs, a citizenship filled with social justice. It will never be possible to completely destroy social inequality; it can be continuously reduced. A progress with social justice constitutes a fundamental aim of the State. Decreasing the dualism in the degrees of citizenship is fostered with enthusiasm. It can come from a basic consensus, in a new auditorium ruled by the federal Constitution in its variation process. As long as a more equal distribution of natural or manufactured goods does not take place, the language of secular scripts would be better understood by those who know the benefits of complete citizenship and know all of its enlightenment.

\section{Palabras clave:}

Estado constitucional, soberanía del pueblo, ciudadanía, igualdad ante el Derecho, igualdad de oportunidades, desigualdad social creciente, 
disminución de la pobreza, justicia social, reparto de bienes yacentes y futuros en una comunidad.

\section{Keywords:}

Constitutional State, Sovereignty of the people, Citizenship, Equality before the law, Equality of opportunity, Growing social inequality, Decrease in poverty, Social justice, Distribution of existing and future goods in a community. 